\title{
UMA PROPOSTA ESQUECIDA - O BANCOR
}

\section{RESUMO}

ESTE ARTIGO INSERE-SE NO CAMPO DO DIREITO MONETÁRIO, E TEM POR OBJETIVO FAZER UM LEVANTAMENTO DA PROPOSTA DE KEYNES NO CONTEXTO DAS DISCUSSÕES POLÍTICAS E ECONÔMICAS, EM BRETTON WOODS, ACERCA DO FUTURO DA REGULAÇÃO MONETÁRIA INTERNACIONAL. A ABORDAGEM AQUI DELINEIA PRINCIPALMENTE O QUE CONSTITUIU A PROPOSTA DA INTERNATIONAL CLEARING UNION E UM DESDOBRAMENTO EM PARTICULAR - O BANCOR. MUITO EMBORA TENHA SIDO DESCARTADO COM AS DEMAIS PROPOSTAS DE KEYNES, O SISTEMA BRETTON WOOdS ACABOU CONSAGRANDO AS PROPOSTAS DE HARRY DEXTER WHITE E, CONSEQUENTEMENTE, A HEGEMONIA DOS ESTADOS UNIDOS NO SISTEMA FINANCEIRO INTERNACIONAL. AdEMAIS, O BANCOR SERVIU DE INSPIRAÇÃO AO QUE HOJE É CONHECIDO COMO DIREITO ESPECIAL DE SAQUe (SPECIAL DRAWING RIGHTS), UNIDADE DE CONTA UTILIZADA PELO Fundo MONETÁrio INTERnACIONAL (FMI).

O LEVANTAMENTO FOI REALIZADO COM BASE EM LEITURA DE TEXTOS DO AUTOR, ARTIGOS ACADÊMICOS ESPECIALIZADOS E EM ATAS DAS REUNIÕES OCORRIDAS EM BRETTON WOODS.

\section{PALAVRAS-CHAVE}

Bretton Woods; Bancor; Direito Especial de Saque; Fundo Monetário INTERnACIONAL; Keynes.
Nicole Julie Fobe

A FORGOTTEN PROPOSAL - THE BANCOR

\section{ABSTRACT}

THIS PAPER APPROACHES THE FIELD OF MONETARY LAW AND MONETARY POLICY, SPECIFICALLY REGARDING THE KEYNES' INTERNATIONAL CLEARING UNION PROPOSAL IN THE BRETTON WOODS ECONOMIC AND POLITICAL CONTEXT. IT ALSO DESCRIBES AND DEEPENS SOME OF THE CURRENT INTERNATIONAL MONETARY SYSTEM'S ELEMENTS, SUCH AS THE SPECIAL DRAWING RIGHTS AND ONE OF THE ICU'S ORIGINALLY IMAGINED PRODUCTS, THE BANCOR. THE BANCOR, EVEN THOUGH DISCARDED ALONG WITH MOST OF KEYNES' PROPOSALS - WHICH STATED HARRY DEXTER WHITE'S AND, CONSEQUENTLY, THE UNITED STATES HEGEMONY IN THE INTERNATIONAL FINANCIAL SYSTEM WOULD BE LATER INSPIRING THE TODAY KNOWN AS SPECIAL DRAWING RIGHTS, ACCOUNTING UNIT USED BY THE INTERNATIONAL MONETARY Fund (IMF).

THE RESEARCH WAS CONDUCTED BASED ON THE AUTHOR'S WRITINGS, ON SPECIALIZED ACADEMIC ARTICLES AND ON TRANSCRIPTS OF THE MEETINGS HELD ON BRETTON WOODS.

\section{KEYWORDS}

BRETTON WOODS; BANCOR; SPECIAL DRAWING RIGHTS; INTERNATIONAL MONETARY FUND; KEYNES.

\section{i O Contexto de Surgimento}

Pouco antes do fim da Segunda Guerra Mundial, em julho de 1944, aconteceu nos Estados Unidos a Conferência de Bretton Woods, que teria por objetivo a discussão de novas políticas financeiras e monetárias de maneira global. Participaram da reunião representantes diplomáticos e governantes das 44 nações aliadas, que terminaram 
não apenas por estabelecer novas regras e padrões ao sistema monetário internacional como por reforçar a hegemonia norte-americana no cenário político e econômico mundial.

As ideias trazidas em Bretton Woods e posteriormente implantadas foram um reflexo direto da experiência dos EUA durante e após a Grande Depressão - período de crise que teve início com a quebra da bolsa de Nova Iorque, em 1929, e se desenrolou ao longo dos anos 1930, influenciando largamente as propostas de política econômica desenvolvidas naquele momento. Os EUA buscavam, em primeiro lugar, uma forma de reforçar o intervencionismo estatal enquanto padrão essencial à criação de políticas públicas eficientes, garantindo uma participação ativa do Estado na promoção e na implantação de políticas públicas, econômicas e sociais. Além disso, enquanto vencedor da Segunda Guerra Mundial e líder das nações aliadas, os Estados Unidos seriam os únicos capazes de financiar as demais nações no pós-guerra. Era essencial, então, não apenas garantir uma maneira mais rápida e fácil de realizar aportes de capitais - como empréstimos ou o repasse por meio de um fundo comum, o que seria posteriormente realizado pelo BIRD - como também assegurar que o empenho de dólares na reconstrução dos países afetados pela guerra tivesse como contrapartida uma preponderância política do país credor. Assim, os representantes norte-americanos rechaçaram quaisquer propostas que implicassem um gasto excessivo por parte da nação aliada ou que não garantissem o poder de mando por parte dos Estados Unidos no que diz respeito ao montante eventualmente desembolsado (ASHERMAN, 1983-1984, p. 246-247; LASTRA, 2000, p. 508-510; WILLIAMS, 1944-1945, p. 43).

Das discussões concluídas, que ficaram polarizadas principalmente entre as propostas do Reino Unido - protagonizadas por John Maynard Keynes - e as norte-americanas - apresentadas por Harry Dexter White -, resultaram o Fundo Monetário Internacional (FMI), o Banco Internacional para Reconstrução e Desenvolvimento (BIRD) e a fixação do dólar enquanto padrão internacional para operações de câmbio. Fixou-se, portanto, a criação de um fundo comum cuja participação majoritária - tanto em termos econômicos como em termos políticos - seria de responsabilidade dos EUA. Isso significa que os Estados Unidos contribuiriam com uma parcela proporcionalmente maior em relação aos demais países, mas ao mesmo tempo obteriam mais quotas no sistema de governança do fundo comum, que seria responsável por oferecer empréstimos a fim de equilibrar déficits no balanço de pagamentos, ao passo que o BIRD atuaria como um banco de fomento aos países subdesenvolvidos, com escopo no financiamento de infraestrutura e serviços básicos, bem como na reconstrução dos países no pós-guerra.

\section{O CONCEITO E JUSTIFICATIVA POR TRÁS DO BANCOR}

O FMI surge, portanto, para sanar, no pós-guerra, eventuais desequilíbrios nas balanças 
comerciais dos países e, com isso, promover a continuidade e posterior desenvolvimento do comércio internacional. A ideia de um "fundo" comum para a promoção do comércio entre países foi trazida, de diferentes formas, tanto por John Maynard Keynes quanto por Harry Dexter White - sendo a proposta de Keynes mais ousada e abrangente: criação de uma Câmara de Compensações Internacionais (International Clearing Union), instituição que teria por objetivo capitalizar de 30 a 35 bilhões de dólares americanos para, em primeiro lugar, saldar as dívidas advindas do período da Segunda Guerra - permitindo, assim, um começo "limpo" das balanças comerciais nas novas transações pós-guerra - e, em segundo lugar, financiar o comércio internacional a longo prazo. A capitalização inicial teria como pressuposto a criação de um fundo comum, cujos recursos viriam do saldo positivo dos países superavitários. A partir desse fundo inicial, seriam realizados empréstimos para alçar os países deficitários à condição de transacionar internacionalmente.

A International Clearing Union (ICU) seria uma espécie de banco central mundial que centralizaria as transações entre países - representados por seus respectivos bancos centrais. O objetivo paralelo da instituição seria a criação de um novo sistema monetário internacional por meio do bancor, cuja única função seria facilitar transações internacionais e estabelecer um padrão monetário que não dependesse de flutuações cambiais ou políticas que variassem de país para país. O bancor, assim, foi concebido como uma moeda puramente escritural, a ser utilizada única e exclusivamente pelos bancos centrais em sede internacional a fim de facilitar as diferentes transações entre países. ${ }^{1}$ Após a capitalização inicial, seriam criadas quotas de acordo com o volume comercial dos países no período pré-guerra. Essas quotas seriam expressas em uma nova unidade de medida internacional - o bancor.

Keynes visava, com a instituição de um novo padrão monetário internacional, sanar dois problemas que, segundo ele, eram inerentes ao padrão-ouro, até então utilizado nas transações comerciais internacionais. Em primeiro lugar, o ouro, por ser um recurso natural, tem disponibilidade limitada na natureza. Esse fato, por si só, já inviabiliza um crescimento vertiginoso da economia, uma vez que, quanto maior o volume das transações comerciais, maior a exigência de meio circulante para embasá-las. Se o meio circulante é insuficiente para acompanhar o crescimento econômico, mais cedo ou mais tarde haverá um problema de liquidez e, com isso, a impossibilidade de realização de novas transações. Além disso, Keynes apontava também o problema do ajuste assimétrico, um déficit na balança comercial de um país que se desenvolveu mais do que seus parceiros. Um país que possui uma renda maior do que os demais tende a canalizar um maior número de bens importados para a sua economia interna, o que gera um desequilíbrio na sua balança comercial (mais importações do que exportações). No padrão-ouro, viam-se duas saídas para este cenário: ou o país deficitário implantava barreiras e desestímulos à importação de bens estrangeiros ou ele necessitaria de empréstimos para cobrir o seu balanço negativo - o que 
não poderia ser feito de forma contínua. O problema do padrão-ouro, na visão de Keynes, era que o sistema terminava por forçar os países deficitários a reduzir sua renda como forma de, paralelamente, reduzir suas importações. Keynes defendia que, na contramão de todo país com um déficit comercial, há países com superávits comerciais (ASHERMAN, 1983-1984, p. 245; LASTRA, 2000, p. 511). A melhor alternativa seria, assim, que os países superavitários aumentassem sua renda a fim de absorver mais importações, promovendo um desenvolvimento econômico concomitante internacionalmente, sem que medidas restritivas reduzissem o volume de transações. A criação de regras monetárias internacionais e a adoção de um meio de pagamento que não fosse afetado pela rigidez da escassez natural seriam formas essenciais de contribuir para um desenvolvimento pleno da economia no período pós-guerra. O bancor, enquanto moeda escritural, possibilitaria a criação de uma liquidez desatrelada de fatores naturais e, paralelamente, tornaria possível que o país deficitário não fosse sempre o único a arcar com desequilíbrios fáticos entre balanças comerciais. ${ }^{2}$

A proposta de um banco central mundial foi rejeitada durante as diversas discussões que ocorrem em Bretton Woods, em razão de dois principais fatores. Primeiro, a criação de uma moeda não física, puramente escritural, era algo ousado demais para um sistema acostumado a lastrear suas transações em ouro. Além disso, abdicar do ouro ou mesmo do dólar implicaria também abdicar de uma certa parcela de soberania e, consequentemente, de poder, no cenário político internacional - o que não é exatamente um fator positivo na exposição de uma proposta. Segundo, a capitalização inicial - avaliada em torno de US\$ 30 bilhões - seria bancada quase integralmente pelos Estados Unidos: afinal, não apenas os EUA contavam com a maior quantidade de dólares do mundo naquele momento, como também eram os únicos a ter a possibilidade de "produzir" a quantia necessária pelo seu banco central. Inundar o mercado americano de dólares traria graves consequências à economia, o que foi considerado um fator decisivo para a rejeição da proposta keynesiana.

O grande vencedor de Bretton Woods, os Estados Unidos, foi representado por Harry Dexter White nas discussões acerca do novo sistema monetário internacional a entrar em vigor. White via como essencial a manutenção dos fluxos comerciais, e não dos fluxos de capitais. Suas propostas estavam centradas no crescimento e proteção do comércio internacional, funções a serem exercidas por um Fundo de Estabilização (em contraposição à Câmara de Compensações proposta por Keynes). Esse Fundo de Estabilização, uma versão preliminar do Fundo Monetário Internacional, contaria com um "baú" de diferentes moedas nacionais, a serem utilizadas posteriormente nas distintas transações comerciais entre países. "A criação de liquidez internacional continuaria dependendo, assim, das políticas monetárias dos países que emitissem essas moedas internacionalmente aceitas." (CARVALHO, [s.d.], p. 9). O plano de White, nesse sentido, não previa nem a criação de liquidez nem a correção do ajuste assimétrico levantado por Keynes. ${ }^{3}$ 
A primazia americana no período pós-guerra foi então sedimentada com a criação de um fundo internacional no valor de 5 milhões de dólares, ${ }^{4}$ sobre o qual os EUA contavam com $25 \%$ dos votos, e culminou com a adoção do dólar enquanto padrão monetário no comércio internacional. ${ }^{5}$

No início dos anos 1960, a política inflacionária adotada pelos Estados Unidos começou a impactar a economia mundial. Na prática, a adoção de uma moeda nacional enquanto meio de pagamento internacional resultou na dependência global direta ao dólar e, indiretamente, às suas políticas econômicas. A contradição do sistema monetário, que posteriormente levou ao fracasso do sistema presidido pelo dólar, residia no fato de que, quanto mais dólares em circulação, menor a confiança na moeda norte-americana. Afinal, o banco central dos EUA podia imprimir moeda, criá-la sem lastro, como e quando bem entendesse. Com o comércio internacional em franco desenvolvimento, a carência por dólares crescia vertiginosamente - entretanto, a demanda crescente deixou de confiar na oferta crescente da moeda americana. Essa contradição ficou conhecida como paradoxo de Triffin, ${ }^{6}$ por ter sido levantada pelo professor Robert Triffin em seu livro $A$ crise do ouro e do dólar. O paradoxo de Triffin levou à suspensão, em 1971, da indexação do dólar ao ouro e, consequentemente, do "abandono" oficial do dólar enquanto moeda padrão nas transações internacionais.

\section{Direito Especial de Saque (DES) e Seu Papel No Fundo Monetário InTERnaCional}

Com o declínio do dólar, surge, no âmbito do FMI, a discussão acerca dos Special Drawing Rights (SDR), ou Direito Especial de Saque. Em teoria, os SDR deveriam assumir três funções, constituindo uma figura mista entre moeda, crédito e reservas: a) somar-se ao dólar enquanto reserva monetária; b) atuar enquanto unidade de medida para transações internacionais; e c) substituir o ouro nas transações realizadas no âmbito do FMI. A terceira função foi desempenhada automaticamente com o colapso do padrão ouro, a primeira função nunca foi implantada e a segunda função é a única que, de fato, continua em vigor. ${ }^{7}$ A primeira emissão de SDR se deu em 1974 a partir de uma capitalização inicial de US\$ 9,5 bilhões, ${ }^{8}$ sendo que os valores foram realocados de acordo com as quotas de cada país membro. Os SDR são a unidade de medida utilizada nas transações entre FMI e países membros, e podem ser trocadas tanto diretamente entre os próprios membros como alocada pelo FMI a algum país como, por exemplo, na forma de um empréstimo. ${ }^{9}$ Desde a sua criação, em 1969, houve 32 transações realizadas em SDR, sendo que 19 delas aconteceram após 2009. ${ }^{10}$

Em agosto de 2009, no auge da crise econômica que teve início em 2008, o FMI editou uma série de medidas ${ }^{11}$ visando à promoção da utilização dos SDR no contexto do comércio internacional. Houve uma nova capitalização, totalizando SDR 204 bilhões, com a distribuição de novas quotas aos membros que aderiram ao FMI 
pós-1981 - já que esses países, por não estarem presentes nas primeiras duas realocações (em 1970 e 1979), ainda não possuíam contas com SDR.

Basicamente, portanto, os SDR são uma unidade de medida - não podendo ser categorizada nem como moeda nem como crédito (são, antes, um direito a crédito, a ser posteriormente traduzido na moeda correspondente) - utilizada pelo FMI como estratégia para aumentar a liquidez internacional. Antes do colapso "oficial” do sistema Bretton Woods em 1973, o seu valor era calculado na paridade 1 SDR = 1 dólar. ${ }^{12}$ Atualmente, o cálculo é feito com base em uma cesta de moedas, ${ }^{13}$ constituída por quatro moedas-chave ao comércio internacional (dólar, euro, iene e libra esterlina, ver Tabela 1), existindo 204 bilhões de SDR em circulação (o equivalente a US\$ 316 bilhões). ${ }^{14}$

Tabela 1 - Cálculo da Quantidade de Moedas na Nova Cesta de DES (DADOS DE 30 DE DEZEMBRO DE 2010)

\begin{tabular}{rllll} 
MOEDA & $\begin{array}{l}\text { (1) PESO } \\
\text { INICIAL (COTA) }\end{array}$ & $\begin{array}{l}\text { (2) QUANTIDADE } \\
\text { ILUSTRATIVA DE } \\
\text { MOEDAS }\end{array}$ & $\begin{array}{l}\text { (3) CÂMBI0 EM } \\
\mathbf{3 0 / 1 2 / 2 0 1 0}\end{array}$ & $\begin{array}{l}\text { (4) EQUIVALENTE } \\
\text { EM DóLAR }\end{array}$ \\
\hline EURO & 37.4 & 0.4230 & 1.32500 & 0.560475 \\
\hline IENE JAPONÊS & 9.4 & 12.1000 & 81.63000 & 0.148230 \\
\hline LIBRA ESTERLINA & 11.3 & 0.1110 & 1.54350 & 0.171329 \\
\hline DÓLAR & 41.9 & 0.6600 & 1.00000 & 0.660000 \\
\hline SDR1 = US\$17 & & & & 1.54003 \\
\hline
\end{tabular}

Valor de cada moeda no cálculo de SDR. Fonte: página do FMI. ${ }^{18}$

\section{Atuais limitações do DES e novas propostas}

\section{PARA A COORDENAÇÃO MONETÁRIA}

Desde o colapso do sistema financeiro em 2008, tem-se discutido tanto no próprio FMI como no ambiente acadêmico uma utilização mais ampla dos SDR, uma vez que o sistema já está em vigor e insere-se em um espaço de debate e cooperação internacional. No entanto, como visto anteriormente, em 40 anos de funcionamento, o número de operações utilizando a unidade de medida ainda não ultrapassou a marca dos 50. A proposta original mais ambiciosa de Keynes - de criação de um verdadeiro meio de pagamento a nível global - encontraria certamente diversos entraves políticos 
- e mesmo econômicos - à sua implantação, principalmente tendo em mente o sistema de quotas adotado pelo FMI e a estrutura de poder daí decorrente.

O sistema de governança do FMI instituído com a criação do órgão refletiu de forma significativa a hegemonia norte-americana consagrada no período pós-guerra. Os Estados Unidos possuem um dos oito assentos permanentes da Diretoria Executiva do órgão (os demais são ocupados por Japão, Alemanha, França, Reino Unido, China, Rússia e Arábia Saudita) e, por deterem também o maior número de quotas com direito a voto (por volta de 17\%), são o único país a possuir, na prática, direito de veto sobre todas as decisões tomadas. ${ }^{19}$

A proporcionalidade entre poder político e contribuição econômica, no entanto, não necessariamente é algo a ser combatido. Em primeiro lugar, quando da criação do sistema de governança do Fundo, os Estados Unidos não teriam contribuído financeiramente com um projeto de reconstrução que não lhes garantisse, em contrapartida, um poder de decisão correspondente quanto à condução das políticas de empréstimo. A participação majoritária norte-americana foi, assim, uma condição à sua adesão ao órgão, e a presença americana - ou, melhor, dos recursos americanos - foi essencial à revitalização da economia dos países afetados pela Segunda Guerra. Não fosse o investimento norte-americano, o cenário comercial internacional teria demorado décadas para se erguer. Cumpre lembrar também que um eventual descasamento entre poder político e investimento econômico pode levar a discrepâncias significativas no nível supranacional, como é o exemplo da União Europeia. Muito embora a Alemanha seja a maior economia do bloco e tenha inclusive financiado países de potencial econômico inferior nos últimos anos, ${ }^{20}$ a sua história - com duas guerras mundiais - e complexo de culpa - decorrente do seu "passado negro" que perdura até hoje -, levaram a um poder político não correspondente à sua participação financeira na comunidade europeia. Isso significa, basicamente, que a Alemanha "paga a conta”, mas não possui poder suficiente para promover decisões acerca de uma política tributária comum, ou medidas mais austeras de empréstimos e financiamento de dívidas. Em suma, o descompasso entre participação política e participação econômica pode levar a discrepâncias contraprodutivas dentro do sistema, e isso acaba por ir de encontro ao interesse dos seus próprios membros.

Talvez fosse interessante, em vez de focar as críticas aos SDR no sistema de governança do FMI - que certamente não é perfeito e poderia ser tornado mais justo e atualizado ao atual contexto mundial -, promover o fortalecimento de um meio de pagamento comum, como foi ambicionado por Keynes nas discussões de Bretton Woods. Isso poderia ser alcançado, em um primeiro momento, por meio da expansão do uso dos SDR não apenas como unidade de medida, e sim efetivamente como moeda transacionável, sendo que o controle das operações seria feito exclusivamente no âmbito do FMI. Assim, os países poderiam começar a adimplir obrigações entre si em SDR (saldando dívidas e oferecendo crédito, por exemplo), e a utilização de 
SDR não estaria restrita somente a transações para e com o Fundo. Esperar que a governança seja reformada primeiro para, em um segundo momento, promover uma reforma do sistema monetário e financeiro internacional é uma proposta que tende a ser rejeitada pelos países hegemônicos, que temem perder sua influência e poder de decisão no âmbito do FMI.

Após a crise de 2008, surgem ou recrudescem no mundo cada vez mais formas alternativas de pagamento entre privados - como é o caso do Bitcoin e das demais moedas virtuais, das moedas sociais, clubes de troca e demais meios de pagamento paralelos - com o objetivo de contornar a escassez de moeda, fugir ao controle errático dos bancos centrais sobre as políticas monetárias nacionais e promover o desenvolvimento por meio da circulação de ativos. Mais cedo ou mais tarde, essa tendência atingirá também o cenário internacional. Quer SDR quer outro mecanismo inovador, fato é que os fluxos comerciais têm exigido um maior volume de recursos financeiros, o que demanda em contrapartida uma maior liquidez e a existência e circulação de ativos estáveis, que garantam segurança ao mercado. O bancor, proposta esquecida após as discussões de Bretton Woods, configura a ideia de uma moeda única global que garantiria, ao mesmo tempo, um desenvolvimento do comércio internacional e uma unificação de políticas monetárias e financeiras. Talvez, com o fortalecimento crescente das relações comerciais entre países no contexto da globalização e a indefinição crescente acerca dos limites da soberania nacional, a ideia de uma política monetária e de uma política financeira comuns torne-se pouco a pouco mais palatável e, quem sabe, também venha a ser, no futuro, possível.

NOTAS

1 “Uma operação de exportações, por exemplo, envolveria o recebimento por um banco no país importador da receita de venda dos bens, sua transferência para o banco central daquele país, que faria a transferência do valor correspondente em bancor para a conta do país exportador, cujo banco central entregaria o contravalor em moeda local ao exportador." (CARVALHO, [s.d.], p. 7)

2 O Plano Keynes previa ainda a imposição de uma multa em bancor ao país superavitário que se recusasse a expandir sua demanda como forma de contribuir para a absorção das exportações de um país deficitário. Dessa forma, a "responsabilidade" sobre um déficit em balança comercial seria repartida entre ambos, não sobrecarregando a economia do país com balanço negativo. Além disso, se um país superavitário tivesse um valor que excedesse determinado limite, a ICU subtrairia o valor excedente e o colocaria em um fundo comum. Essa "subtração" também tinha como objetivo incentivar países superavitários a aumentar o seu nível de absorção de exportação de outros países. 
3 White trouxe, em suas propostas, a possibilidade de criação de uma unidade de conta chamada unitas, a ser utilizada no âmbito do FMI como forma de facilitar cálculos de transações. Diferentemente do bancor, o unitas não foi concebido como meio de troca, ou seja, não poderia promover o pagamento de transações.

4 Enquanto no Plano White os EUA deveriam contribuir com US\$ 3,2 milhões dentre os US\$ 5 milhões que constituiriam o fundo, o Plano Keynes requereria um dispêndio de aproximadamente US\$23 milhões por parte do país norte-americano.

5 Na Seção 1(a), Artigo IV do documento constitutivo do Fundo Monetário Internacional, ficou instituído que "The par value of the currency of each member shall be expressed in terms of gold as a common denominator or in terms of the United States dollar of the weight and fineness in effect on July 1,1944".

6 “ $[\mathrm{O}]$ mundo todo precisava de dólares para poder acomodar a expansão do comércio internacional, mas dólares se tornavam disponíveis para outros países quando os Estados Unidos tinham déficits em suas operações externas e pagavam pela diferença enviando dólares ao exterior, aumentando a liquidez internacional; esse aumento de liquidez, contudo, ao ser gerado por déficits nos pagamentos dos Estados Unidos, contribuía para enfraquecer a confiança no próprio dólar. Quanto mais liquidez fosse criada, maior seria a desconfiança no valor da moeda americana." (CARVALHO, [s.d.], p. 11)

7 Sobre a composição dos Direitos Especiais de Saque e o porquê da sua denominação, Duncan Cameron enuncia: "What was created when the SDR account suddenly appeared on the books of the IMF? Was it money? Credit? Reserves? The short answer is that SDRs are a hybrid of all three. Because each of the standard terms was a 'loaded phrase' and had acquired political connotations over the course of the protracted negotiations, it was necessary to find a neutral expression; thus 'drawing rights', with 'special' being added to distinguish them from ordinary drawings within the IMF"(CAMERON, 1980-1981, p. 724).

8 Naquele momento, os SDR totalizavam 4\% das reservas mundiais de capital.

9 Os empréstimos calculados em SDR também têm os seus respectivos juros calculados com base na unidade de medida. Os valores são atualizados diariamente e estão disponíveis no site do FMI: <http://www.imf.org/external/np/fin/ data/sdr_ir.aspx>. Acesso em: 27 jul. 2014.

10 Todas as informações referentes aos SDR foram retiradas do site do FMI: <http://www.imf.org/ external/ about/sdr.htm\#members>. Acesso em: 21 nov. 2014.

11 As medidas são explicitadas pelo próprio FMI no site disponível em: <http://www.imf.org/external/np/exr/ facts/ sdr.HTM>. Acesso em: 21 nov. 2014.

12 À época, também era possível adquirir 1 SDR com o equivalente a 0.888671 gramas de ouro - valor "em espécie" do dólar.

13 O cálculo é revisado a cada cinco anos pelo Comitê Executivo do FMI, momento em que se analisa o peso de cada moeda no cenário comercial a fim de providenciar o equilíbrio do valor do SDR. A próxima revisão será em 2015.

14 Informações retiradas do site do FMI. Íntegra disponível em: <https://www.imf.org/external/np/exr/facts/ sdr.HTM>. Acesso em: 27 jul. 2014.

15 As quantidades de moeda são baseadas no valor de câmbio médio durante o período de $1^{\circ}$ de outubro a 30 de dezembro de 2010.

16 O câmbio do Iene japonês está expresso em termos de unidade monetária por dólar; os demais câmbios foram expressos em dólar por unidade monetária.

17 O valor arredondado, em dólares, de uma unidade de DES.

18 Para os valores atualizados diariamente, ver a cotação em < http://www.imf.org/external/np/fin/data/ rms_sdrv.aspx >, acesso em 27 jul. 2014. 
19 As grandes decisões no FMI (como é o caso das alterações estatutárias) devem ser tomadas por maioria qualificada de $85 \%$ dos votos. Assim, os EUA têm um poder de veto "legal", especificado nos estatutos, e um poder de veto "fático", baseado no fato de deterem $17 \%$ dos votos.

20 É o caso, por exemplo, dos aportes financeiros feitos pelo país no âmbito do Fundo Europeu de Estabilização Financeira (EFSF) e do Mecanismo Europeu de Estabilidade (ESM). No primeiro, a Alemanha investiu 211 bilhões de euros (de um total de 440 bilhões de euros que constituem o Fundo. Dados retirados de planilha do EFSF. Disponível em: <http://www.efsf.europa.eu/attachments/faq_en.pdf>, acesso em: 11 dez. 2014). Já no Mecanismo Europeu de Estabilidade a Alemanha aparece como a maior investidora de recursos, representando $27 \%$ do capital investido. Dados retirados dos estatutos da organização, que podem ser consultados no site disponível em: <http://www.esm.europa.eu/ about/legal-documents/index.htm>, acesso em: 21 nov. 2014.

\section{REFERÊNCIAS BIBLIOGRÁFICAS}

ASHERMAN, Jeanne. “The International Monetary Fund: A History of Compromise”, 18 N.Y.U. J. Int'l L. \& Pol. 235 1983-1984.

CAMERON, Duncan. "Special drawing rights”, 36 International Journal 713 1980-1981.

CARVALHO, Fernando Cardim. Bretton Woods aos 60 anos. Disponível em:

<www.ie.ufrj.br/moeda/pdfs/bretton_woods_aos_60_anos.pdf>. Acesso em: 25 jul. 2014.

INTERNATIONAL CLEARING UNION, HL Deb 18 May 1943 vol. 127 cc521-64. Disponível em: <http://hansard. millbanksystems.com/lords/1943/may/18/international-clearing-union>. Acesso em: 25 jul. 2014.

KEYNES, John M. Proposals for an International Currency (Clearing) Union, 11 fev. 1942.

LASTRA, Rosa Maria. “The International Monetary Fund in Historical Perspective”, Journal of International Economic Law, 2000.

WEST, Philip J. "Special Drawing Rights, the United States Dollar and the World's Monetary Reserves”. Australian International Law Journal 36, 1994-1995.

WILLIAMS, John. "International Monetary Plans after Bretton Woods". 23 Foreign Aff. 38 1944-1945.

XIAOCHUAN, Zhou. "Reform the international monetary system”, BIS Review 41/2009. 